\title{
Development of a Computer Code for the Interpretation of Results of Hot Plane Strain Compression Tests
}

\author{
B. KOWALSKI, C. M. SELLARS ${ }^{11}$ and M. PIETRZYK \\ Akademia Górniczo-Hutnicza, Wydział Metalurgii i Inżynierii Materiałowej Al. Mickiewicza 30, 30-059 Kraków, Poland. \\ 1) IMMPETUS, Institute for Microstructural and Mechanical Process Engineering, The University of Sheffield, Sheffield S1, \\ 3JD UK.
}

(Received on May 29, 2000; accepted in final form on August 31, 2000)

\begin{abstract}
In the present work an investigation of constitutive equations is made to obtain good fit to experimental data and ensure proper extrapolation out of experimental range of plane strain compression tests to low and high values of Zener-Hollomon parameter, which are required in finite element modelling. A computer program for optimisation of rheological parameters of material was developed. Optimisation using experimental data for two ultra low carbon steels was made and the results are compared with measured stress-strain curves. The obtained constitutive equations were used in the finite element model and comparison between experimental and computed displacement-force curves is made. The influence of inhomogeneity of strain rate, strain and temperatures distribution during compression tests on flow curves is illustrated.
\end{abstract}

KEY WORDS: constitutive equations; optimisation; FE modelling; dynamic recrystallisation; steel; plane strain compression.

\section{Introduction}

Compression tests are most often carried out when the rheological parameters of material in metal forming processes need to be determined. Friction between tools and specimen, deformational heating and heat transfer to the tool are phenomena, that affect the results of all tests. It can be concluded that the main difficulty in the interpretation of the results of tests is connected with the inhomogeneity of deformation, which due to various factors, depends on the type of the test. Finite element simulation of plastometric tests allows the prediction of the real state of deformation, accounting for all phenomena causing the inhomogeneity. However, for numerical analysis of metal flow and heat transfer in metal forming processes, these models require a description of the material properties, which are introduced in the program in the form of constitutive equations. The modelling approach, which assumes that the constitutive parameters of the material are known, is often used and is called the direct method. Since the main objective of performing a mechanical test is to determine the material parameters, the application of the direct method is limited. This fact led to the development of a new parameter estimation method, which is known as the inverse method. The general idea of this method is based on a combination of the finite element simulation of the test with measurements of the overall parameters of this test, such as the force or torque. ${ }^{1-5)}$ Measurements of the process parameters are compared with the predictions by the finite element method. The error norm is defined as a vector of distances between these measured and calculated values. The minimisation of error norm is used to determine the unknown parameters in constitutive equations. However linking the finite element model with the objective function results in very long computing time for optimisation. The objectives of the present work are formulated with the above remarks in mind. Simplification of the calculation process is made in two steps. The first step is optimisation using only experimental data for one specimen geometry at assumed conditions of compression test such as strain rate and temperature. It is taking account only an average distribution of strain and strain rate. To include the effect of local values of these parameters the second step of optimisation should be made. Results obtained from a FE model of the plane strain compression test for different geometry of specimens (different starting thickness) can be used for optimisation. Constitutive equations for the second step can be taken from the first step. This allows account to be taken of inhomogeneity of deformation and cuts the time of calculation. This publication describes the first step of the solution. Optimisation of experimental data is done with constraints, so that the necessary limitations are imposed on the stress-strain function.

Numerous works of various researchers ${ }^{6)}$ show that selection of the function describing stress-strain curves is crucial for accuracy of the simulation. Several types of equations used as constitutive laws are not capable of describing behaviour of materials showing dynamic softening phenomena. The capability of equations suggested in Ref. 7) to describe complex flow stress behaviours of metals is 
Table 1. Chemical composition of the experimental steels.

\begin{tabular}{|l|l|l|l|l|l|l|l|l|}
\hline Steel & $\% \mathrm{C}$ & $\% \mathrm{Si}$ & $\% \mathrm{Mn}$ & $\% \mathrm{P}$ & $\% \mathrm{~S}$ & $\% \mathrm{Al}$ & $\% \mathrm{Ti}$ & $\mathrm{Nppm}$ \\
\hline A & 0.003 & 0.02 & 0.22 & 0.074 & 0.014 & $<0.005$ & 0.009 & 31 \\
\hline B & 0.005 & 0.02 & 0.22 & 0.020 & 0.017 & 0.013 & 0.08 & 24 \\
\hline
\end{tabular}

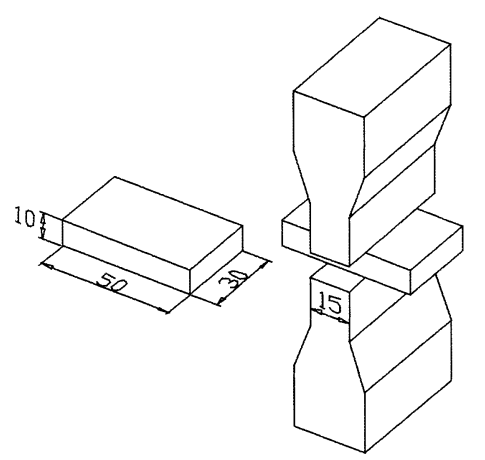

Fig. 1. Schematic diagram of test geometry.

investigated in this work using optimisation techniques. The definition of the error norm is discussed.

\section{Experimental Procedure}

Experimental ultra low carbon (ULC) steels were produced by vacuum melting and casting into $76 \mathrm{~mm}$ dia. ingots, with hot tops. The chemical composition of the steels is given in Table 1. The ingots were machined to $73 \mathrm{~mm}$ dia., reheated in a protective atmosphere to $1170^{\circ} \mathrm{C}$ for $1 \mathrm{hr}$ and hot extruded using fuminite lubrication to $30 \mathrm{~mm} \times$ $15 \mathrm{~mm}$ bar. Specimens for plane strain compression testing measuring $30 \mathrm{~mm}$ wide $\times 10 \mathrm{~mm}$ thick $\times 50 \mathrm{~mm}$ long were machined and chromium plated ( $15 \mu \mathrm{m}$ hard chromium). Glass lubricant was applied to the specimens and dried overnight before specimens were reheated to $1100^{\circ} \mathrm{C}$ for $20 \mathrm{~min}$. After reheating the specimens were removed from the reheating furnace, air cooled to the testing temperature and held in the test furnace for 2 min to eliminate temperature gradients. The nominal testing temperatures were 950 , 1000 and $1050^{\circ} \mathrm{C}$. Actual temperatures were recorded from a thermocouple inserted to the centre of the specimen. In Fig. 1 the test geometry is shown. Tests were carried out at the University of Sheffield using a $500 \mathrm{kN}$ servo-hydraulic machine with computer control, at constant equivalent strain rates of $1,7.5$ and $49 \mathrm{~s}^{-1}$ to total equivalent strains $\varepsilon \approx 1.5-2.0$. Load, displacement and temperature were recorded as a function of time during the tests. Specimens were water quenched to room temperature immediately after testing. The load and displacement data were converted from raw data to equivalent stress-equivalent strain curves and also pressure-equivalent strain using an analysis program. ${ }^{8)}$ Instantaneous strain rate was also computed.

Instantaneous temperature was computed using a finite difference thermal model of the plane strain compression test developed by Foster ${ }^{9,10)}$ because it was found that thermocouples did not always remain in the centre of the deformation zone.

\section{Constitutive Equations}

The constitutive equations fitted to the experimental data

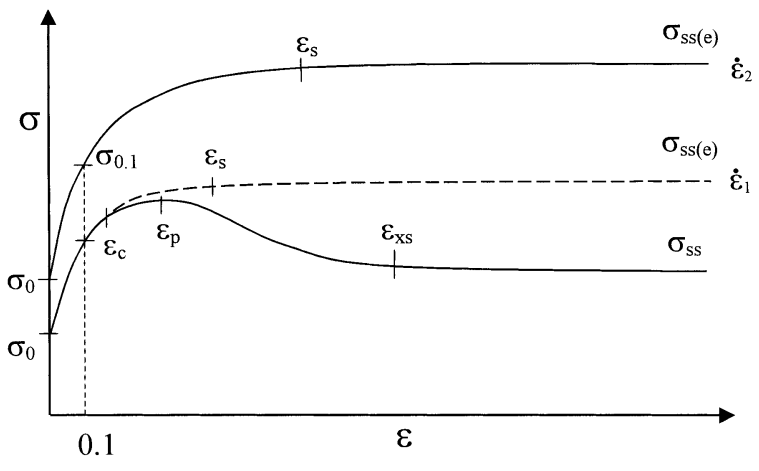

Fig. 2. Schematic stress-strain curves for hot deformation at constant strain rates and constant temperature.

are empirical, but do correlate directly with the microstructure evolution arising from effects of work hardening and the dynamic softening mechanisms of recovery and recrystallisation. It is possible to define a set of discrete characteristic points on the experimental flow stress curve (Fig. 2).

$\sigma_{0}:$ stress at the onset of plastic strain

$\sigma_{0.1}: \quad$ stress at an equivalent strain of 0.1

$\sigma_{\text {ss(e) }}$ : steady state flow stress arising from the balance of work hardening and dynamic recovery only.

$\sigma_{\text {ss }}$ : steady state flow stress arising when dynamic recrystallisation takes place

$\sigma_{\mathrm{s}}$ : strain to the onset of steady state by work hardening and recovery only

This is defined as the strain at which

$$
\frac{\sigma-\sigma_{0}}{\sigma_{\mathrm{ss}(\mathrm{e})}-\sigma_{0}}=0.98
$$

$\varepsilon_{\mathrm{c}}:$ strain for onset of dynamic recrystallisation

$\varepsilon_{\mathrm{p}}$ : strain at which peak flow stress occurs as a result of softening by dynamic recrystallisation

$\varepsilon_{\mathrm{xs}}$ : strain at the "onset" of steady state when dynamic recrystallisation occurs.

This is defined as the strain at which

$$
\frac{\sigma_{(\mathrm{e})}-\sigma}{\sigma_{\mathrm{ss}(\mathrm{e})}-\sigma_{\mathrm{ss}}}=0.98
$$

All these characteristic stresses and strains depend on strain rate $\dot{\varepsilon}\left(\mathrm{s}^{-1}\right)$ and temperature $T(\mathrm{~K})$. For this purpose the Zener-Hollomon parameter $Z$ combines the effect of both parameters as

$$
Z=\dot{\varepsilon} \exp \left(\frac{Q_{\mathrm{def}}}{R T}\right)
$$

where $Q_{\text {def }}$ is activation energy of deformation and $R$ is gas constant.

The dependence of the characteristic stress values on $Z$ can be described by the hyperbolic sine relationship ${ }^{11}$

$$
Z=A^{*}\left(\sinh \left(\alpha^{*} \sigma^{*}\right)\right)^{n^{*}}
$$

where $A^{*}, \alpha^{*}, n^{*}$ are constants for each characteristic stress $\sigma^{*}$.

Ultimately the relationship between $\alpha$ and $Z$ can be expressed in the form 


$$
\sigma^{*}=\frac{1}{\alpha^{*}} \sinh ^{-1}\left(\frac{Z}{A^{*}}\right)^{1 / n^{*}}
$$

It is, therefore, imperative that the equations do not cross at very low $Z$, otherwise the solution will collapse. In order to connect the characteristic stresses to form a stress-strain curve, the following equation is applied when only work hardening and dynamic recovery occur ${ }^{7)}$

$$
\sigma_{(\mathrm{e})}=\sigma_{0}+\left(\sigma_{\mathrm{ss}(\mathrm{e})}-\sigma_{0}\right)\left[1-\exp \left(-\frac{\varepsilon}{\varepsilon_{\mathrm{r}}}\right)\right]^{1 / 2}
$$

where $\varepsilon_{\mathrm{r}}$ is a characteristic strain which defines the curvature between $\sigma_{0}$ and $\sigma_{\mathrm{ss}(\mathrm{e})}$. From the earlier definition of $\varepsilon_{\mathrm{s}}$,

$$
\begin{aligned}
& 0.98=\left[1-\exp \left(-\frac{\varepsilon_{\mathrm{s}}}{\varepsilon_{\mathrm{r}}}\right)\right]^{1 / 2} \\
& \varepsilon_{\mathrm{r}}=\frac{\varepsilon_{\mathrm{s}}}{3.23}
\end{aligned}
$$

It was found ${ }^{12)}$ that

$$
\varepsilon_{\mathrm{s}}=a+b\left(\sigma_{\mathrm{ss}(\mathrm{e})}\right)^{2}
$$

where $a$ and $b$ are constants dependent on the specific steel.

When dynamic recrystallisation occurs, the stress-strain curve in its absence is first defined as described above and the additional softening is then calculated as

$$
\frac{\sigma_{(\mathrm{e})}-\sigma}{\sigma_{\mathrm{ss}(\mathrm{e})}-\sigma_{\mathrm{ss}}}=1-\exp \left[\left(-\frac{\varepsilon-\varepsilon_{\mathrm{c}}}{\varepsilon_{\mathrm{xr}}-\varepsilon_{\mathrm{c}}}\right)\right]^{m}
$$

The form of above equation is the equivalent to an Avrami equation for static recrystallisation and assumes that the fractional softening is directly proportional to the fraction recrystallised.

$$
\sigma=\sigma_{(\mathrm{e})}-\left(\sigma_{\mathrm{ss}(\mathrm{e})}-\sigma_{\mathrm{ss}}\right)\left\{1-\exp \left[-\left(\frac{\varepsilon-\varepsilon_{\mathrm{c}}}{\varepsilon_{\mathrm{xr}}-\varepsilon_{\mathrm{c}}}\right)\right]^{m}\right\}
$$

when $\varepsilon>\varepsilon_{\mathrm{c}}$

The characteristic strain constant $\varepsilon_{\mathrm{xr}}$ defines the strain interval over which the first cycle of recrystallisation occurs. From the earlier definition of $\varepsilon_{\mathrm{xs}}$ and Eq. (9), when $m=2$,

$$
0.98=1-\exp \left[-\left(\frac{\varepsilon_{\mathrm{xs}}-\varepsilon_{\mathrm{c}}}{\varepsilon_{\mathrm{xr}}-\varepsilon_{\mathrm{c}}}\right)\right]^{2}
$$

which leads to

$$
\varepsilon_{\mathrm{xr}}-\varepsilon_{\mathrm{c}}=\frac{\varepsilon_{\mathrm{xs}}-\varepsilon_{\mathrm{c}}}{1.98}
$$

It was found ${ }^{11)}$ that

$$
\varepsilon_{\mathrm{c}}=C_{\mathrm{c}}\left(\frac{Z}{\sigma_{\mathrm{ss}(\mathrm{e})}^{2}}\right)^{N_{\mathrm{c}}}
$$

and

$$
\varepsilon_{\mathrm{xs}}-\varepsilon_{\mathrm{c}}=C_{\mathrm{x}}\left(\frac{Z}{\sigma_{\mathrm{ss}(\mathrm{e})}^{2}}\right)^{N_{\mathrm{x}}}
$$

It is considered that when deformation conditions lead to values of $\varepsilon_{\mathrm{c}}>\varepsilon_{\mathrm{s}}$ dynamic recrystallisation no longer takes place. The constitutive model described in this section is used in the following sections together with optimisation and the obtained material constants are included in an FE model of the plane compression test.

\section{Methodology}

A user friendly computer program performing optimisation for stress-strain relationships has been developed. The program is based on three optimisation methods: Simplex, ${ }^{13)}$ Rosenbrock $^{14)}$ and the Simulated annealing method. ${ }^{15)}$ The presented results have been obtained using Simplex and Rosenbrock methods. The time required to find the optimum in the Simulated annealing method is much longer than for the other methods. This method could be useful to find a starting point for other more accurate methods.

The objective function for minimisation is defined as the error norm, which yields the difference between measured stresses $\sigma_{\mathrm{m} i}$ and their mathematical representation $\sigma_{\mathrm{c} i}$.

$$
\Phi=\sqrt{\frac{1}{n} \sum_{i=1}^{n}\left(\frac{\sigma_{\mathrm{m} i}-\sigma_{\mathrm{c} i}}{\sigma_{\mathrm{m} i}}\right)^{2}}
$$

Experimental data on work done were used to determine instantaneous mean temperature using the Foster program accounting for both deformational heating and the heat transfer between specimen and tools. Such heat transfer or heat generation may mask the true shape of the stress-strain curve. Instantaneous values of Zener-Hollomon parameter for each point of experimental data were obtained by Lagrangian interpolation of the results from the Foster model $^{9,10)}$ for non-isothermal flow stress curves. The next step was an optimisation using the stress and temperature data until the convergence criterion was achieved. The formulation of the algorithm is shown in Fig. 3.

\section{Results}

To find the proper material constants it is necessary to obtain a good fit of calculated curves to experimental data. For optimisation, results from 9 experimental stress-strain curves were used, for three strain rates: $1,7.5,49 \mathrm{~s}^{-1}$, and for three temperatures: $950,1000,1050^{\circ} \mathrm{C}$. Constants calculated by applying the analysis procedures ") "by hand" (Figs. 4(a)-4(c)) were used as starting point for optimisation. The improvement of the quality of approximation would require meeting two conditions, based on analysis of, how various parameters $\left(\sigma_{0}, \sigma_{\mathrm{ss}(\mathrm{e})}, \sigma_{\mathrm{ss}}, \sigma_{\mathrm{c}}, \sigma_{\mathrm{s}}\right)$ depend on $Z$. The first condition is not to allow crossing of the $\sigma_{0}$ curve at low values of $Z$ (below the experimental range) by other characteristic stress curves such as $\sigma_{0.1}, \sigma_{\mathrm{ss}(\mathrm{e})}$ and $\sigma_{\mathrm{ss}}$. It is well known that this could cause collapse of the FE so- 


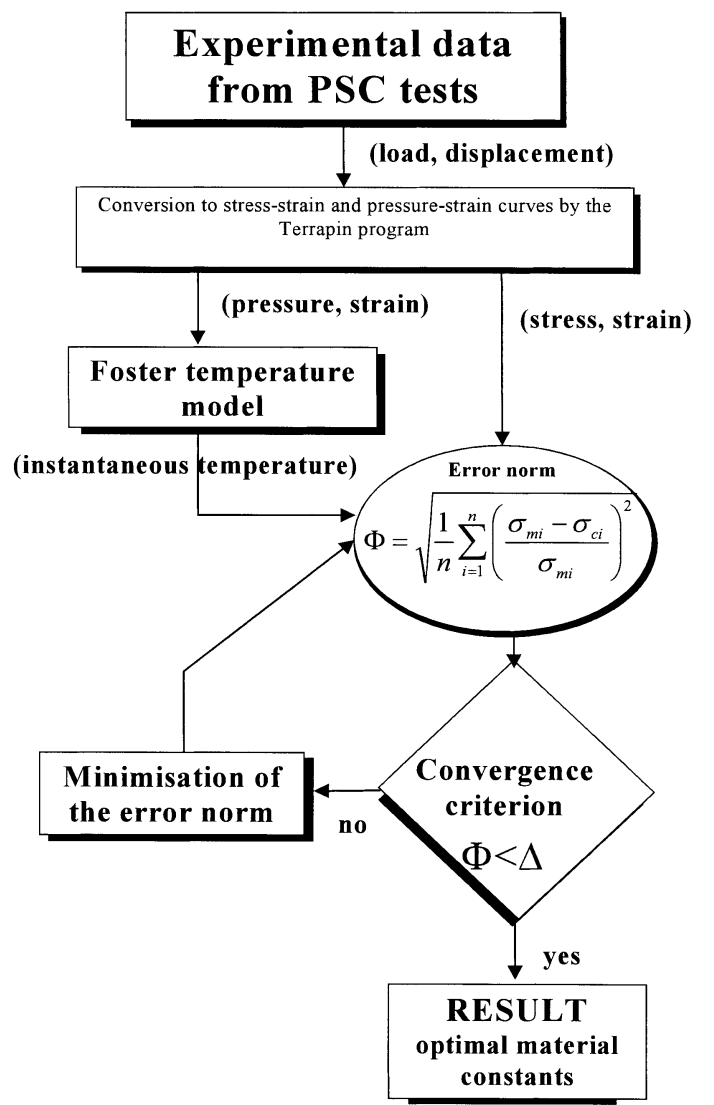

Fig. 3. Formulation of algorithm of optimisation method.

lution. The second condition is to ensure the same value of $Z$ for crossing of $\sigma_{\mathrm{ss}}$ by $\sigma_{\mathrm{ss}(\mathrm{e})}$ and $\sigma_{\mathrm{c}}$ by $\sigma_{\mathrm{s}}$. It is well known that the point where $\sigma_{\mathrm{ss}}$ crosses $\sigma_{\mathrm{ss}(\mathrm{e})}$ indicates when dynamic recrystallisation no longer takes place. When $\varepsilon_{\mathrm{c}}$ crosses $\varepsilon_{\mathrm{s}}$, dynamic recrystallisation no longer takes place and this should be for the same value of Zener-Hollomon parameter.

The constants calculated "by hand" ensured the first condition of not crossing the $\sigma_{0}$ curve at lower values of $Z$ by the other curves (Fig. 5(a)). There was, however incompatibility between the $\sigma_{\mathrm{ss}(\mathrm{e})}-\sigma_{\mathrm{ss}}$ and $\varepsilon_{\mathrm{c}}-\varepsilon_{\mathrm{s}}$ crossing points (Figs. 5(a) and 5(b)). It was found in Ref. 7) that using the same value of $n^{*}$ ensures the Eq. (3) do not extrapolate to unacceptable values at low $Z$. Optimisation with this constraint ensured the first condition, there was no longer crossing between $\sigma_{0}$ and the rest of characteristic stresses. However, incompatibility was noticed from these figures as the same value of $n^{*}$ for the three characteristic stresses led to huge divergences between crossing points for $\sigma_{\mathrm{ss}}$ by $\sigma_{\mathrm{ss}(\mathrm{e})}$ and $\varepsilon_{\mathrm{c}}$ by $\varepsilon_{\mathrm{s}}$. To correct this, a function defined as distance between two crossing points was added to the value of the objective function (14) and the $n_{\mathrm{ss}}$ constant was optimized as a separate variable. To prevent crossing between curves $\sigma_{0}$ and $\sigma_{\mathrm{ss}}$, optimisation with a penalty coefficient was used. When the $\sigma_{\text {ss }}$ curve was less than $\sigma_{0}$ the penalty value was added to the error norm (14). That value was calculated as follows:

$$
\varphi_{\sigma}=\sigma_{0}-\sigma_{\mathrm{ss}}+\lambda
$$

where $\lambda$ is an extra value which is supposed to ensure that there is always a lower value of $\sigma_{0}$ than $\sigma_{\text {ss }}$ at any value of (a)

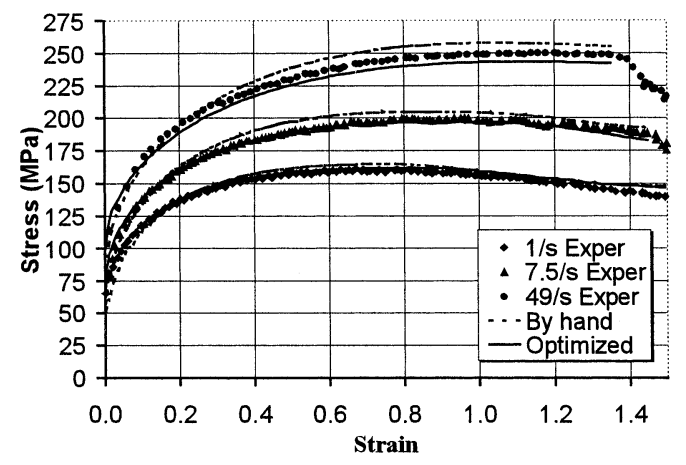

(b)

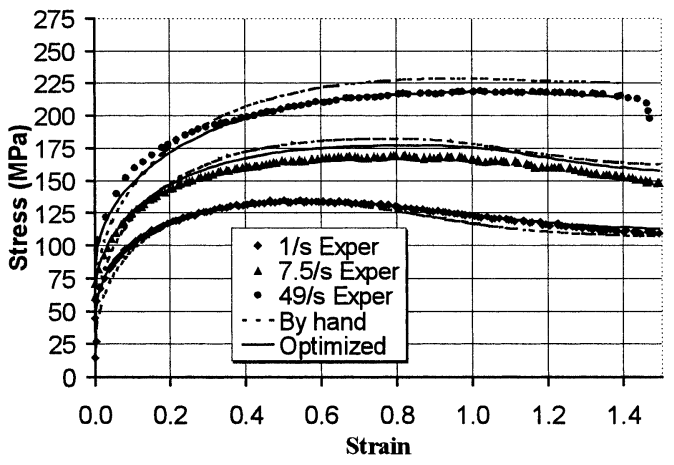

(c)

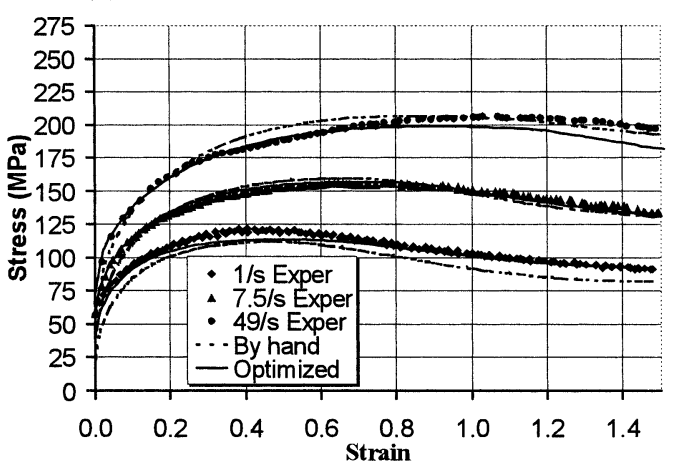

Fig. 4. Stress-strain curves based on constants calculated using "by hand" and optimisation methods compared with the experimental data of Steel A for 950 (a), 1000 (b) and $1050^{\circ} \mathrm{C}(\mathrm{c})$.

$Z$ (Figs. 6(a) and 6(b)). The flow curves fitted by optimisation with the penalty coefficient for Steel A are presented in Figs. 4(a)-4(c). A similar optimisation was performed for Steel B. A comparison between optimized curves from experimental data for Steel A and for Steel B is made with the experimental curves for Steel B in Figs. 7(a) and 7(b). The material constants for the two steels are given in Table 2.

In order to assess the robustness of the optimisation procedure, material constants derived for $\mathrm{C}-\mathrm{Mn}$ steel and given in Table 2 were used as an alternative starting condition to optimise the experimental data for Steel A. The optimised constants from this procedure are shown in the final column of Table 2 and the optimised curves for the highest, middle and lowest values of $Z$ are shown in Fig. 8 . 
(a)

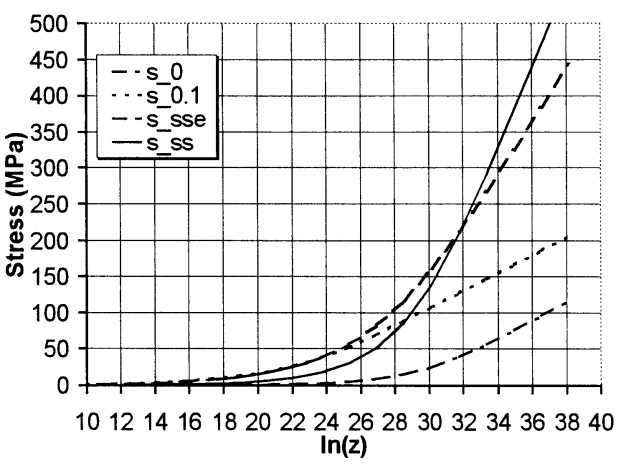

(b)

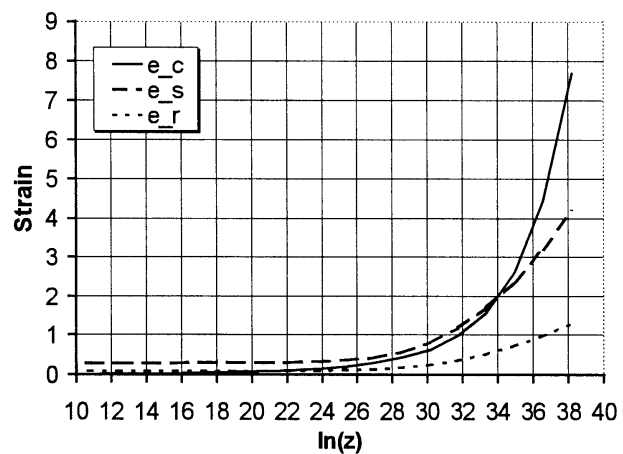

Fig. 5. Steel A-dependence of characteristic stresses (a) and strains (b) on Zener-Holomon parameter for constants calculated from "by hand" method, where: $\mathrm{s}_{-} 0=\sigma_{0}$, $\mathrm{s} \_0.1=\sigma_{0.1}, \quad$ s_sse $=\sigma_{\mathrm{sse}}, \quad \mathrm{s} \_\mathrm{ss}=\sigma_{\mathrm{ss}}, \quad$ e_c $=\varepsilon_{\mathrm{c}}, \quad$ e_s $=\varepsilon_{\mathrm{s}}$, e_r $\mathrm{r}=\varepsilon_{\mathrm{r}}$.

(a)

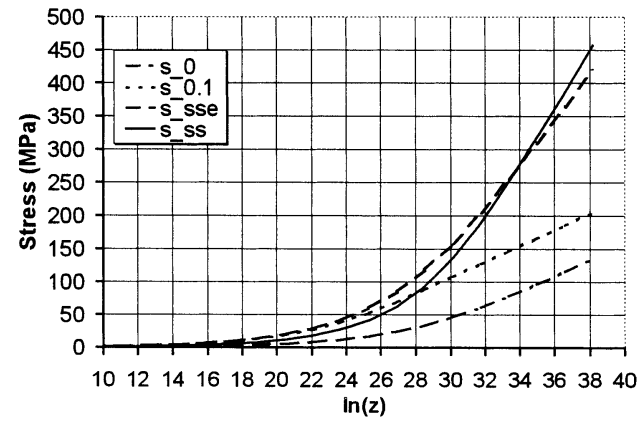

(b)

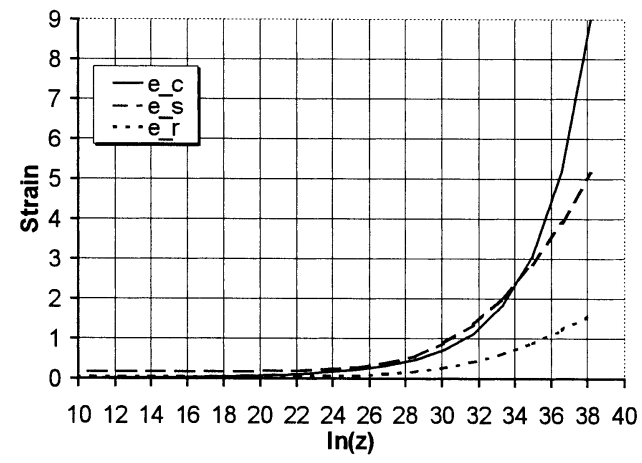

Fig. 6. Steel A-dependence of characteristic stresses (a) and strains (b) on Zener-Holomon parameter for constants calculated from optimisation with penalty coefficient $\lambda$, where: $\quad$ s_ $0=\sigma_{0}, \quad$ s_ $0.1=\sigma_{0.1}, \quad$ s_sse $=\sigma_{\text {sse }}, \quad$ s_ss $=\sigma_{\text {ss }}$, $\mathrm{e} \_\mathrm{c}=\varepsilon_{\mathrm{c}}, \mathrm{e} \_\mathrm{s}=\varepsilon_{\mathrm{s}}, \mathrm{e} \_\mathrm{r}=\varepsilon_{\mathrm{r}}$. (a)

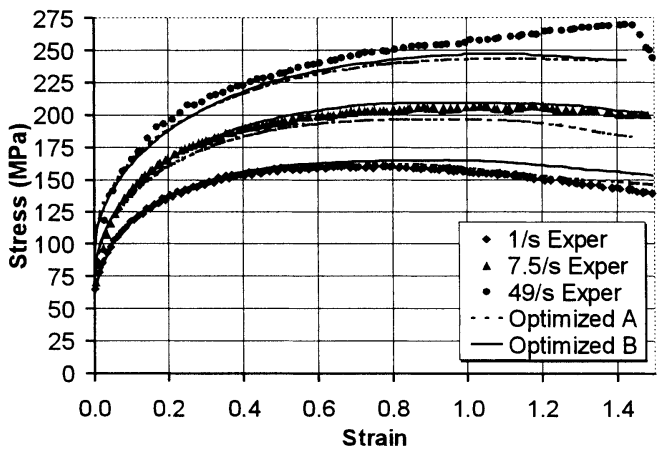

(b)

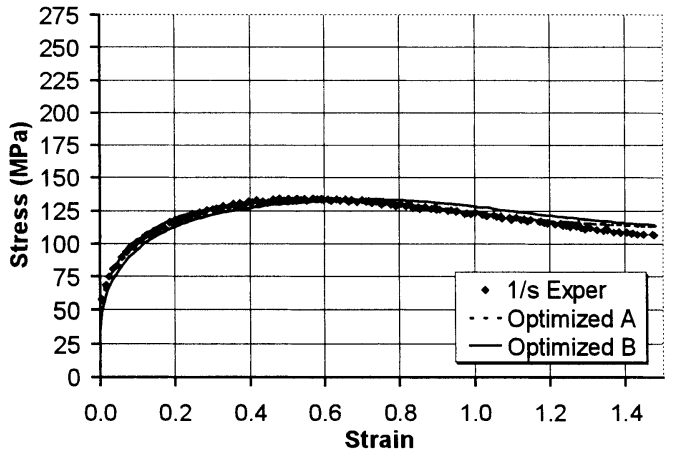

(c)

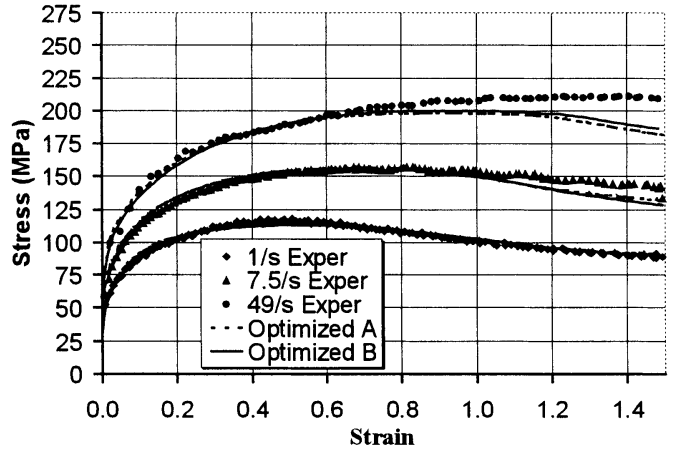

Fig. 7. Stress-strain curves based on constants calculated using optimisation with penalty coefficient $\lambda$ for Steel A and Steel B compared with the experimental data for Steel B at mean temperatures $950^{\circ} \mathrm{C}(\mathrm{a}), 1000^{\circ} \mathrm{C}$ (b) and $1050^{\circ} \mathrm{C}$ (c).

Table 2. Optimised and calculated "by hand" constants.

\begin{tabular}{|c|c|c|c|c|c|}
\hline & \multicolumn{2}{|c|}{ A } & B & C-Mn & A \\
\hline & Calculated & Optimised & Optimised & Original & From C-Mn Steel \\
\hline $\mathrm{A}_{0}$ & $3.350 \mathrm{E}+13$ & $1.305 \mathrm{E}+13$ & $1.150 \mathrm{E}+14$ & $4.647 \mathrm{E}+12$ & $2.140 \mathrm{E}+12$ \\
\hline $\mathrm{n}_{0}$ & 3.010 & 4.344 & 5.180 & 4.225 & 4.316 \\
\hline$\alpha_{0}$ & $2.590 \mathrm{E}-02$ & $1.866 \mathrm{E}-02$ & $1.460 \mathrm{E}-02$ & $1.448 \mathrm{E}-02$ & $2.408 \mathrm{E}-02$ \\
\hline $\mathrm{A}_{\mathrm{ss}(\mathrm{e})}$ & $4.680 \mathrm{E}+12$ & $4.731 \mathrm{E}+12$ & $2.480 \mathrm{E}+12$ & $3.248 \mathrm{E}+12$ & $4.260 \mathrm{E}+12$ \\
\hline $\mathrm{n}_{\mathrm{ss}(\mathrm{e})}$ & 4.035 & 4.344 & 5.180 & 4.225 & 4.316 \\
\hline$\alpha_{\mathrm{ss}(\mathrm{e})}$ & $6.600 \mathrm{E}-03$ & $6.608 \mathrm{E}-03$ & $7.171 \mathrm{E}-03$ & $6.666 \mathrm{E}-03$ & $6.664 \mathrm{E}-03$ \\
\hline $\mathrm{A}_{\mathrm{ss}}$ & $1.610 \mathrm{E}+13$ & $1.649 \mathrm{E}+13$ & $1.020 \mathrm{E}+13$ & $1.966 \mathrm{E}+13$ & $1.920 \mathrm{E}+13$ \\
\hline $\mathrm{n}_{\mathrm{ss}}$ & 2.962 & 3.751 & 2.690 & 3.929 & 3.828 \\
\hline$\alpha_{\mathrm{ss}}$ & $5.900 \mathrm{E}-03$ & $6.052 \mathrm{E}-03$ & $6.433 \mathrm{E}-03$ & $6.076 \mathrm{E}-03$ & $6.044 \mathrm{E}-03$ \\
\hline $\mathrm{a}$ & $3.000 \mathrm{E}-01$ & $1.729 \mathrm{E}-01$ & $4.243 \mathrm{E}-01$ & $3.153 \mathrm{E}-02$ & $2.417 \mathrm{E}-01$ \\
\hline $\mathrm{b}$ & $1.970 \mathrm{E}-05$ & $2.820 \mathrm{E}-05$ & $1.940 \mathrm{E}-05$ & $2.639 \mathrm{E}-05$ & $2.780 \mathrm{E}-05$ \\
\hline $\mathrm{C}_{\mathrm{c}}$ & $1.550 \mathrm{E}-04$ & $1.701 \mathrm{E}-04$ & $1.090 \mathrm{E}-02$ & $1.171 \mathrm{E}-04$ & $1.380 \mathrm{E}-04$ \\
\hline $\mathrm{N}_{\mathrm{c}}$ & $4.160 \mathrm{E}-01$ & $4.168 \mathrm{E}-01$ & $1.896 \mathrm{E}-01$ & $4.008 \mathrm{E}-01$ & $4.241 \mathrm{E}-01$ \\
\hline $\mathrm{C}_{\mathrm{x}}$ & $1.677 \mathrm{E}+01$ & $1.961 \mathrm{E}+01$ & 9.181 & $2.759 \mathrm{E}+01$ & $1.911 \mathrm{E}+01$ \\
\hline $\mathrm{N}_{\mathrm{x}}$ & $-1.430 \mathrm{E}-01$ & $-1.463 \mathrm{E}-01$ & $-9.132 \mathrm{E}-02$ & $-1.420 \mathrm{E}-01$ & $-1.363 \mathrm{E}-01$ \\
\hline $\mathrm{m}$ & 2 & 2 & 1.975 & 2 & 2 \\
\hline
\end{tabular}




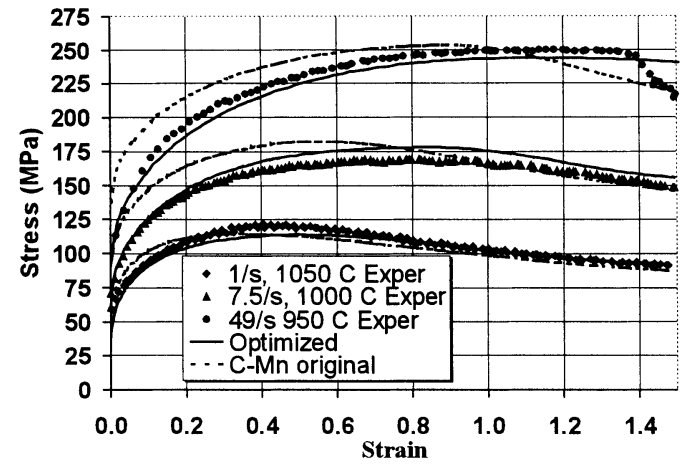

Fig. 8. Stress-strain curves based on constants calculated using optimisation where material constants from C-Mn steel were used as the starting point compared with the experimental data of Steel A at mean strain rates $49,7.5 \mathrm{~s}^{-1}$, $1 \mathrm{~s}^{-1}$, and at mean temperatures 950,1000 and $1050^{\circ} \mathrm{C}$.

\section{Discussion}

Fitting constitutive equations to experimental plane strain compression data using statistical methods "by hand" is tedious and needs a long time to perform calculations even using spreadsheets like Microsoft Excel. Applying this method also gives other difficulties such as choosing characteristic points from experimental flow curves $\left(\sigma_{0}, \sigma_{\mathrm{ss}(\mathrm{e})}\right.$, $\sigma_{\mathrm{ss}}, \varepsilon_{\mathrm{p}}$ ); quite often values of these points have to be interpolated. The optimisation method used to obtain material constants for constitutive equations cuts the time of calculation to a few minutes including data file preparation. It can be seen that the fit of the optimised flow curves to the experimental data is also better than for the curves calculated "by hand" (Figs. 4(a)-4(c)). Using optimisation methods gives another opportunity, which is to optimise the characteristic curves for $\sigma_{0}, \sigma_{\mathrm{ss}(\mathrm{e})}, \sigma_{\mathrm{ss}}, \varepsilon_{\mathrm{c}}, \varepsilon_{\mathrm{r}}$ and $\varepsilon_{\mathrm{s}}$ as functions of Zener-Hollomon parameter by including additional constraints, which ensure compatibility with the physics of dynamic recrystallisation (Figs. 6(a) and 6(b)). As was discussed in previous section, it is essential to ensure the same point of crossing of $\sigma_{\mathrm{ss}}$ by $\sigma_{\mathrm{ss}(\mathrm{e})}$ and $\varepsilon_{\mathrm{c}}$ by $\varepsilon_{\mathrm{s}}$. The optimised curves which satisfy these requirements, Figs. 4(a)-4(c) are within $\pm 5 \%$ of the experimental curves for all strains and deformation conditions. This compares favourably with typical experimental reproducibility of $\pm 3 \%$.

In Figs. 7(a)-7(c) it can be seen that the optimised curves from data for Steel A and Steel B are almost indistinguishable and both agree with the experimental curves within the same limits as for Steel A (Figs. 4(a) to 4(c)) except at the highest strain rate and $\varepsilon>1.0$ when lubrication breakdown (i.e. increased coefficient of friction) appears to have taken place in the experiments. The constants for Steel A or B in Table 2, which in some cases appear to have differences, thus give rise to almost identical stress-strain curves over the experimental range of Zener-Hollomon parameter, which includes the transition from dynamic recrystallisation to dynamic recovery only. Either set of constants can therefore be considered as providing accurate constitutive equations for ULC steels.

To prove the robustness of the method of optimisation, material constants for C-Mn steel were used as an alternative starting point. Results from this starting point are very similar to curves obtained by previous optimisations (Fig.
8) indicating that it may be possible to use data for C-Mn steel as the starting point for optimisation of data for a range of steels. During this research it was also found that by using optimised constants for Steel A as a starting point for optimisation of data for C-Mn steel a good fit of optimised curves was obtained. For the ULC steel, a number of tests were carried out in which the strain rate was changed up or down by an order of magnitude over an equivalent strain of about 0.5 . The experimental stress-strain curves could not be quantitatively compared with curves computed from the optimised constitutive equations obtained from constant strain rate tests because of the large scatter in instantaneous strain rates obtained by differentiation of the experimental displacement-time curves. However, the shapes of experimental and computed curves were always similar, indicating that considering the optimised constitutive equations as being mechanical equations of state (i.e. independent of strain history) in finite element modelling plane strain compression of ULC steels should be valid.

Traditional interpretation of compression tests results is based on an assumption of homogeneous strain and temperature distributions in the deformation zone. Taking into account the inhomogeneity of the deformation caused by the friction, tool geometry and the nonuniform temperatures resulting from deformational heating would allow estimation of the local properties of material. Application of the finite element method to the simulation of the plane strain compression test enables consideration of real conditions in the deformation zone by the evaluation of the local values of the strain rates, strains and temperatures. ${ }^{16)}$ In the present work a finite element simulation of the test was carried out to investigate material constants of constitutive equations obtained by optimisation. Simulation was performed using a computer program for plane strain compression tests developed in Krakow. ${ }^{17,18)}$ This program assumes a rigid-plastic material model, which obeys the Levy-Mises flow rule and the Huber-Mises yield criterion.

Figures 9(a)-9(c) show calculated distributions of effective strain rate, effective strain and temperature during compression for an assumed starting test temperature of $950^{\circ} \mathrm{C}$.

The constitutive model with constants obtained from optimisation was used in the calculations. The Coulomb friction model with friction coefficient $\mu=0.1$ was applied. Analysis of the results in Figs. 9(a)-9(c) shows strong inhomogeneity of all investigated parameters in the deformation zone. Thus, strain rates presented in Fig. 9(a) vary between about 0.8 and $1.6 \mathrm{~s}^{-1}$ in the deformation zone at a nominal equivalent strain of 0.8 . Important variations of strain of 0.5 to 1.0 are also seen in Fig. 9(b), but with contours of different shape from Fig. 9(a). The effect of deformational heating is seen in Fig. 9(c).

Similar results of distribution of effective strain rate, effective strain, effective stress and temperature were observed for the assumed test temperatures 1000 and $1050^{\circ} \mathrm{C}$, using the constants in the constitutive model determined using the optimisation technique.

The calculations performed using the finite element code allow one to conclude that full interpretation of the results of plane strain compression tests presents serious difficulties. This test involves significant inhomogeneity of deformation, therefore, local values of strains, strain rates, stress- 
(a)

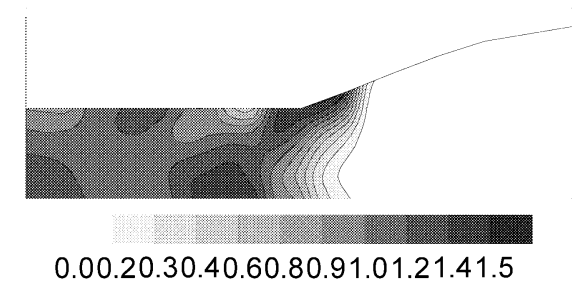

(b)

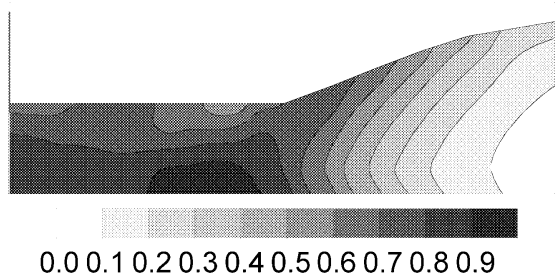

(c)

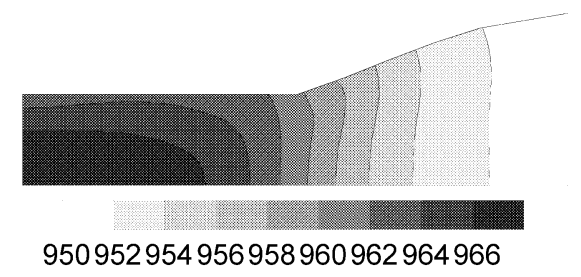

Fig. 9. Distribution of (a) strain rate, (b) strain and (c) temperature calculated using optimised material constants for start deformation temperature $950^{\circ} \mathrm{C}$ at nominal equivalent strain 0.8 and equivalent strain rate $1 \mathrm{~s}^{-1}$.

es and temperatures may differ from the average values. Research carried out in the present work suggests that the optimisation technique should be combined with a finite element model. However, such a procedure would require extremely long computing times. Application of the technique described in this paper constrains the area of search and decreases this time significantly. In consequence, the starting point close to the final solution is generated. With this newly obtained starting point much less iterations combined with the finite element code will be needed. However, simplification of this combined procedure is inevitable and is the subject of continuing research.

\section{Conclusions}

Research on the interpretation of the results of plane strain compression tests on ULC steel is described in the work. It is shown that the optimisation technique allows one to obtain good agreement between measured and calculated stress-strain curves. Particular care should be paid to con- trol the shape of curves describing characteristic strains and stresses as a function of the Zener-Hollomon parameter. Therefore an optimisation with constraints has to be applied. It has been proved that material constants for constitutive equations for different steels can be used as starting point to obtain the same optimized fit to flow curves for other steels. Using optimisation techniques significantly cuts calculation time. Combination of optimisation techniques with finite element computation to take account of inhomogeneity of strain rate, strain and temperature distribution is important to fit experimental plane strain compression test data to local deformation conditions, but excessive computation times would be required unless a simplified procedure can be developed.

\section{Acknowledgements}

The authors thank A. J. Lacey for carrying out the PSC tests and for providing the curves fitted "by hand" to the test data.

\section{REFERENCES}

1) J. C. Gelin and O. Ghouati: J. Mater. Process. Technol., 34 (1994), 435.

2) J. Kusiak, M. Pietrzyk and J. G. Lenard: Proc. NUMIFORM '95, ed. by S. F. Shen, P. R. Dawson, Ithaca, (1995), 277.

3) Z. Malinowski, J. Kusiak and M. Pietrzyk: Proc. Conf. Application of Mathematical Methods in Science and Technique, Wydawnictwo "SCRIPTUM" inz. Waclaw Wyroba Kraków, 2 (1995), 43.

4) S. Khoddam, Y. C. Lam and P. F. Thomson: Steel Res., 67 (1996), 39.

5) A. Gavrus, E. Massoni and J. L. Chenot: J. Mater. Process. Technol., 60 (1996), 447.

6) F. Grosman: Proc. CCME '97, ed. by R. Ciesielski, B. Ciszewski, J. Z. Gronostajski, H. Hawrylak, J. Kmita and S. Kobielak, Wydzial Mechaniczny, Politechnika Wroclawska Wrocław, (1997), 67.

7) S. B. Davenport, N. J. Silk, C. N. Sparks and C. M. Sellars: Mater. Sci. Technol., 16 (2000), 1.

8) N. J. Silk and M. R. Van Der Winden: Mater. Sci. Technol., 15 (1999), 295.

9) S. R. Foster: PhD Thesis, University of Sheffield, (1981).

$10)$ R. J. Hand, S. R. Foster and C. M. Sellars: Mater. Sci. Technol., 16 (2000), 442.

11) C. M. Sellars and W. J. McG. Tegart: Mem. Sci. Rev. Met., 63 (1966), 731. (in French)

12) C. M. Sellars: Ironmaking Steelmaking, 22 (1995), 459.

13) J. A. Nedler and R. Mead: Comp. Jour, 7 (1965), 308.

14) R. Bellman: Modern Analytic and Computational Methods in Science and Mathematics, American Elsevier Publishing Company, Inc., New York, (1968).

15) T. Masters: Sieci neuronowe w praktyce. Programowanie w jezyku $\mathrm{C}++$, WNT, Warszawa, (1996).

16) M. Pietrzyk and J. E. Tibbals: Proc. COMPLAS. Vol. 4, ed. by D. R. J. Owen, E. Onate and E. Hinton, Pineridge Press, Barcelona, (1995), 889-900.

17) M. Pietrzyk and J. G. Lenard: Thermal-Mechanical Modelling of the Flat Rolling, Process, Springer-Verlag, Berlin, (1991).

18) M. Pietrzyk, J. G. Lenard and G. M. Dalton: Ann. CIRP, 42 (1993), 331. 